\title{
Does m-health based exercise (guidance plus education) improve efficacy in patients with chronic low-back pain囚A preliminary report on the intervention's significance
}

\section{Fuming Zheng}

First Affiliated Hospital of Sun Yat-sen University

\section{Shufeng Liu}

First Affiliated Hospital of Sun Yat-sen University

\section{Shanshan Zhang}

First Affiliated Hospital of Sun Yat-sen University

\section{Qiuhua yu}

First Affiliated Hospital of Sun Yat-sen University

\section{Wai Leung Ambrose Lo}

First Affiliated Hospital of Sun Yat-sen University

\section{Tingni Li}

First Affiliated Hospital of Sun Yat-sen University

Chuhuai Wang ( $\square$ wangchuh@mail.sysu.edu.cn)

First Affiliated Hospital of Sun Yat-sen University

\section{Research Article}

Keywords: m-health, chronic low-back pain, patient education, core-stability exercise, COVID-19

Posted Date: May 13th, 2021

DOI: https://doi.org/10.21203/rs.3.rs-488182/v1

License: (c) (1) This work is licensed under a Creative Commons Attribution 4.0 International License. Read Full License 


\section{Abstract}

Objectives: The utilization of mobile health (m-health) has rapidly expanded during the COVID-19 pandemic, and there is still a lack of relevant clinical data pertaining to chronic low-back pain『CLBP『management. This study was designed to compare the effectiveness of $\mathrm{m}$-health based exercise (via guidance plus education) versus exercise (via guidance) during CLBP management.

Methods: Participants ( $n=40$ ) were randomly assigned to intervention and control groups. The intervention group received $\mathrm{m}$-health based exercise (via guidance plus education), whereas the control group received $\mathrm{m}$-health based exercise (via guidance). The exercise prescription video and educational content were sent to participants by the application (app), Ding Talk. Repeated-measures analysis of variance was used to test the baseline's intervention

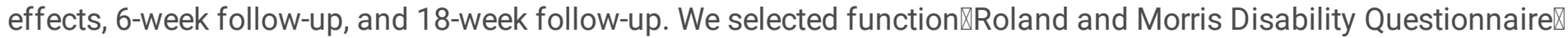
and pain intensity (current, mean, and most severe Numeric Rating Scale in the last 2 weeks $\llbracket$ as the primary outcomes, changes of negative emotion (depression, anxious), and quality of life as the secondary outcomes.

Results: Time's significant effect was found in pain, function, and health-related quality of life in both groups, but time did not show significant interaction effects. Participants were able to use m-based education with their anxiety and depression after treatment, but the relief only lasted until Week 6. No differences were found on the aspect of mental health-related quality of life.

Conclusion: M-health based exercise (via guidance) is a convenient and effective method to treat CLBP. Additionally, plus education is more helpful in relieving short-term negative emotions and improving treatment adherence than

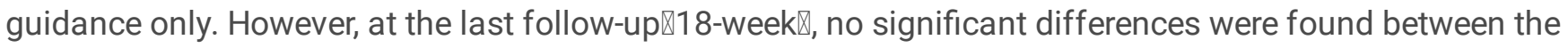
intervention and control groups.

\section{Introduction}

Chronic low-back pain (CLBP) is a very common symptom that can occur in different age groups (from the young to the elderly ${ }^{[1]}$. CLBP prevalence can start early in life ${ }^{[2]}$. According to the 2019 Global Burden of Disease Study, lowback pain is one of the top ten causes of DALYs in both the 10 to 24 -year and 25 to 49 -year age groups ${ }^{[3]}$. CLBP causes not only physical suffering but also psychological and social problems ${ }^{[4]}$. There are a wide range of interventions available for CLBP and international guidelines that emphasize the self-management approach based on a biopsychosocial model[5-7].

Core stability exercise (CSE) has been proven useful for CLBP within short-term durations ${ }^{[8]}$. However, patients with CLBP have poor adherence to exercise training without supervision, leading to poor long-term outcomes ${ }^{[9]}$. We suggest that there are two reasons for poor adherence. One is the lack of remote guidance after the patient leaves the hospital, and the second is the lack of patient education. Education for patients with CLBP plays a critical role in influencing patients' self-management. For example, the back school is a very effective method for alleviating $\mathrm{CLBP}^{[10]}$. However, most traditional education models are still based on a biomechanical approach; research has shown that the biopsychosocial model education seems to be more effective ${ }^{[11]}$. Additionally, medical resources are unevenly distributed in China ${ }^{[12]}$,as a result, patients in remote areas have difficulty in receiving accurate and scientific-educational information. With the emergence of mobile health ( $m$-health), solutions to difficult problems are provided $^{[13-14]}$. A preliminary study suggested that application (app)-based patient self-management has a better effect $^{[15]}$. Since the beginning of 2020 , Covid-19 began to globally spread, and it's impact may last until 2025 ${ }^{[16]}$. The most effective method to control the epidemic is social isolation ${ }^{[17]}$. Covid-19 has influenced the rapid development of 
m-health ${ }^{[18]}$. The idea of developing a home-based fundamental approach to alleviating low-back pain during pandemic has been proposed ${ }^{[19}[$ but it is unknown whether $\mathrm{m}$-health based exercise (via guidance plus education) improves efficacy in patients with CLBP.

Our study aim was to conduct patient-centered research to teach patients in using m-health for CLBP selfmanagement. We hypothesized that $m$-health based exercise (via guidance plus education) would improve function, life quality, pain relief, depression, and anxiety compared to m-health based exercise (via guidance only), and education can also improve treatment adherence.

\section{Methods}

\subsection{Overall design}

This was a single-blinded, pilot parallel-group randomized (1:1) controlled trial. The participants were managed by the Ding Talk V.5.0, which is a smart mobile office platform specially created for global enterprises and organizations produced by Alibaba. It can be used for more effective communication and online data collection. The trial was prospectively registered with the Chinese Clinical Trials Registry Number: ChiCTR2000041459(12/26/2020).

\subsection{Participants}

The participants were recruited from October 4, 2020 to November 1, 2020 via WeChat, a social networking tool in China. Participants were screened via electronic questionnaire (provided by Ding Talk). Eligible subjects were invited to complete the pretrial questionnaire.

Participants were eligible for inclusion if they were between the ages of 18 and 65 , had CLBP within a minimum of a 12-week duration. Participants with back pain associated with a specific diagnosis (e.g., spinal stenosis, lumbar disc herniation, and lumbar fracture), who had difficulty in participation (e.g., unable to master the Ding Talk apps or unable to speak Chinese) or not interested in the trial, were excluded. A total of 52 people signed up, and we selected 40 eligible participants through detailed online consultation. All participants provided online informed consent for trial participation and electronic signatures for participation in treatment.

\subsection{Randomization and blinding}

Following the baseline assessment, the 40 eligible participants were numbered and randomly divided into two groups by IBM SPSS statistics 22 to receive $\mathrm{m}$-health based exercise (via guidance; control group; CG) or $\mathrm{m}$-health based exercise (via guidance plus education; intervention group; IG). Participants were informed that the trial was comparing two different forms of online self-management exercise before allocation; they didn't know each other's treatment method. Since the outcomes were self-reported, bias from the assessors was avoided. The researchers were blind to the study.

\subsection{Interventions}

The intervention time was 6 weeks; the participants were asked to complete the exercise at least 3-times per week. The exercise instruction was provided by a physiotherapist with three years of experience, and patient education was provided by a rehabilitation physician. All treatments were performed online.

\subsubsection{M-health based exercise guidance}

Both groups received exercise videos designed by physiotherapist, which included two sections: stretching and strengthening (Fig. 2). The first week's main topic was to teach the participants how to use Ding Talk. We uploaded a 
daily-CSE video, then we taught the participants how to record perception; for the weekends, we asked them to complete an exercise log to answer the following questions: (1) How's the exercise going? (2) Do you have any questions about the interventions? (3) How is your CLBP changing?

For the next five weeks, the participants were asked to perform the exercise at least 3-times a week with a corresponding record. Each exercise lasted between 20 and 45 minutes, and we reminded the participants to finish the recording log over the weekend. After reviewing the recording logs, we replied to each comment, either by encouraging or answering question to maintain effective researcher-participant communication.

\subsubsection{M-health based patient education}

Additionally, the intervention group received the CLBP-education online lessons. In the first course week, the rehabilitation physician organized an online meeting for members to introduce themselves and share their experiences pertaining to low-back pain. After understanding the participants' basic information, the weekly topics were formulated as follows:(1)Week 2: What is CLBP? (2) Week 3: How does CLBP appear? (3) Week 4: How does CES work? (4) Week 5: Identify bad lifestyle habits, such as being sedentary. (5) Week 6: Conclusion and expectation. To ensure that every participant could receive educational information, we required weekly study-report submissions on what participants learned for that week. The study report was open, and the group members could see each other. We encouraged group communication to form a positive social environment.

\subsection{Follow-up}

Participants scanned the provided QR codes to complete the questionnaire at baseline (before randomization) and after randomization at Week 6 (post treatment) and Week 18. Participants were compensated with cash through combine lucky red envelopes (A random red envelope reward includes electronic cash of 1 to 5 yuan) for each followup.

\subsection{Outcome measurements}

Sociodemographic and back pain information was obtained at baseline (Table 1). All primary and secondary outcomes were administered at each time point (baseline, Week 6, Week 18).

\subsubsection{Primary outcome}

We selected two primary outcomes, the Roland Morris Disability Questionnaire (RMDQ) ${ }^{[20]}$, which measures back pain disability (scale 0-24; higher scores indicate greater functional limitation.) and the Numeric Rating Scale (NRS) [21], which measures mean pain intensity during the last 2 weeks (scale $0-10$, higher scores indicate greater pain intensity). We selected three NRS types: average NRS (average pain intensity over the last 2 weeks), current NRS (current pain intensity), and most sever NRS (most severe pain intensity over the last 2 weeks).

\subsubsection{Secondary outcome}

Secondary outcomes consisted of mental and physical health-related quality of life by use of the 36-item short form health survey (SF36), which included physical and mental health summary (PCS and MCS) scales; we calculated the results based on Hong Kong-specific scoring algorithms ${ }^{[22]}$; anxiety was measured using the Generalized Anxiety Disorder-7 (GAD-7; range, 0-21; higher scores indicated greater severity) ${ }^{\text {[23]; }}$; depressive symptoms were assessed using the Self-Rating Depression Scale (SDS; range, 25-100; higher scores indicated greater severity/minor depression: 53-62; moderate depression: 63-72; major depression: over 72$)^{[24]}$. Treatment adherence was indicated by the completion of the weekend exercise log $\amalg$ nonadherence was not completed once; incomplete adherence was completed less than 6 times, and complete adherence was completed all 6 times. 


\subsection{Statistical Analysis}

We used intent-to-treat approach to analyse all available data at baseline, Week 6 , and Week 18 . We compared groups on baseline demographic and clinical characteristics using $\chi 2$ tests(or Fisher's exact probability method)for categorical variables. For the continuous variable, normality tests were first tested. When the results fit, we used the independent t-test; when the results did not fit, we chose the rank sum test. Analyses of the primary and secondary continuous outcome variables were analyzed using two way repeated-measures ANOVA. When the results did not conform to the Mauchly test, we used Greenhouse-Geisser to proofread. The interaction effect was first tested. When the results were significant, between-group differences were tested at $a=0.05$ at each time point. When the results were not significant, the main effect of group and time was next tested. Otherwise, Bonferroni correction was applied at each time point, with p-values adjusted by multiplying the nominal p-value by the number of tests; partial etasquared $\left(\nabla_{p}^{2}\right)$ was reported to demonstrate the effect size. The outcome variable's missing final values were replaced by the last known value before the participant lost to follow-up. All data were analyzed using IBM SPSS Statistics V.22.

\section{Results}

A total of 52 participants were screened for eligibility, and 40 met eligibility criteria; they were randomized into two groups between November 2, 2020 and December 14, 2020, with the final follow-up on March 6, 2021 (Fig. 1). We found that most participants 28 (70\%) chose massage for treatment-only 11 (27.5\%) chose exercise for treatment, and 22 (55\%) did not live in Guangzhou, including 1 (2.5\%) who was studying abroad (Japan). The participants' baseline characteristics are presented in Table 1. Participants' educational attainment was generally high. RMDQ, current NRS, GAD-7, and MCS scores did not fit a normal distribution, so we used the rank sum test to compare. The intervention group's degree of depression and physical health summaries were worse than the control group, and the results showed significant differences. No significant differences were found in other baseline data. No adverse events related to the intervention or control group were noted.

The primary outcome measures included function (RMDQ score) and pain (NRS score; Table 2, Fig. 3). Although the RMDQ and the NRS did not show significant interaction effects, a significant effect of time was found in both scores; the main effect of group did not show a significant difference. There were three levels of time factor, so post-hoc analysis was made. Comparing the baseline, the RMDQ score was at 6 weeks (mean deviation, $-0.820 ; 95 \% \mathrm{Cl},-1.606$ to -0.034 ) and at 18 weeks (mean deviation, $-1.613 ; 95 \% \mathrm{Cl},-2.430$ to -0.796 ); the effect size was $\otimes^{2}=0.406$; the average NRS was at 6 weeks (mean deviation, $-0.993 ; 95 \%$ Cl, -1.684 to -0.303 ) and at 18 weeks (mean deviation, $-1.046 ; 95 \%$ $\mathrm{Cl},-1.834$ to -0.258 ); the effect size was $\rrbracket^{2}=0.262$. The most severe NRS was at 6 weeks (mean deviation, $-1.075 ; 95 \%$ $\mathrm{Cl},-1.794$ to -0.356 ) and at 18 weeks (mean deviation, $-2.176 ; 95 \% \mathrm{Cl},-3.040$ to -1.312 ); the effect size was $\mathbb{\Xi}^{2}=0.423$. Differences on the current NRS pain measure between groups did not reach statistical significance $(P=0.061)$.

The secondary outcome measures are also presented in Table 2 and Fig. 3. Only the PCS of SF-36 showed a significant effect of time. Comparing the baseline, the PCS scores were at 6 weeks (mean deviation, 2.454; $95 \% \mathrm{Cl}$, -0.201 to 5.109$)$ but did not reach statistical significance $(P=0.078)$ and at 18 weeks (mean deviation, $5.823 ; 95 \% \mathrm{Cl}$, 2.900 to 8.745 ). At the treatment end, anxiety and depression levels in the intervention group improved compared to the control group but not by Week 18(Figure 3). The treatment adherence rate is presented in Table 3.

The within group change (mean, SEM) of primary outcomes are shown for RMDQ(A),Average NRS in the last 2 weeks $\square \square \square$ Current NRS $\triangle \mathrm{C} \otimes$, and Most severe NRS in the last 2 weeks. The secondary outcomes are shown for

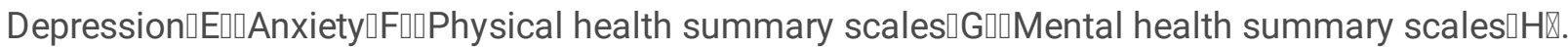


Table 1. Baseline Characteristics of Participants by Treatment Group

\begin{tabular}{|c|c|c|c|}
\hline & Intervention group $\mathrm{aN}=\mathbf{2 0 0}$ & Control group $[\mathrm{N}=20[$ & P Value \\
\hline Age, mean (SD) & $34.0 \otimes 14.4 \rrbracket$ & $34.9 \rrbracket 14.5 \rrbracket$ & 0.853 \\
\hline Female, n (\%) & $14 \bigotimes 70 \bigotimes$ & $12 \rrbracket 60 \rrbracket$ & 0.507 \\
\hline BMI, mean (SD) & $21.5 \llbracket 2.7 \rrbracket$ & $22.3 \rrbracket 3.6 \rrbracket$ & 0.457 \\
\hline \multicolumn{4}{|l|}{ Working status, n (\%) } \\
\hline Employed & $15 \rrbracket 75 \rrbracket$ & $16 \rrbracket 80 \rrbracket$ & \multirow[t]{2}{*}{0.705} \\
\hline Unemployed/Retired & $5 \rrbracket 25 \rrbracket$ & $4 \rrbracket 20 \rrbracket$ & \\
\hline \multicolumn{4}{|l|}{ Education level, n (\%) } \\
\hline primary school or less & $1 \otimes 5 \rrbracket$ & $0 \rrbracket 0 \rrbracket$ & \multirow[t]{4}{*}{0.518} \\
\hline Junior & $1 \otimes 5 \rrbracket$ & $1 \rrbracket 5 \rrbracket$ & \\
\hline Senior & $3 \otimes 15 \rrbracket$ & $1 \otimes 5 \rrbracket$ & \\
\hline College or higher & $15 \rrbracket 75 \rrbracket$ & $18 \varangle 90 \rrbracket$ & \\
\hline \multicolumn{4}{|l|}{ Pain duration, n (\%) } \\
\hline$\leq 1$ year & $6 \rrbracket 30 \bigotimes$ & $5 \rrbracket 25 \rrbracket$ & \multirow[t]{3}{*}{0.407} \\
\hline$<5$ years & $7 \rrbracket 35 \rrbracket$ & $11 \rrbracket 55 \rrbracket$ & \\
\hline$\geq 5$ years & $7 \rrbracket 35 \rrbracket$ & $4 \rrbracket 20 \bigotimes$ & \\
\hline RMDQ & $4.8 \llbracket 2.7 \rrbracket$ & $4.0 \otimes 2.7 \rrbracket$ & 0.332 \\
\hline AVERAGE NRS in the last 2 weeks & $4.7 \otimes 1.8 \rrbracket$ & $4.0 \otimes 1.7 \rrbracket$ & 0.244 \\
\hline Current NRS & $3.4 \bigotimes 1.8 \rrbracket$ & $3.2 \bigotimes 1.8 \rrbracket$ & 0.815 \\
\hline Most severe NRS in the last 2 weeks & $6.6 ه 2.0 \otimes$ & $6.2 ه 1.8 \rrbracket$ & 0.452 \\
\hline SDS & $47.9(11.5)$ & $41.6(7.7)$ & 0.048 \\
\hline GAD-7 & $4.7(2.8)$ & $3.3(3.1)$ & 0.079 \\
\hline SF-36 PCS & $39.5(6.4)$ & $44.3(7.7)$ & 0.042 \\
\hline SF-36 MCS & 48.3(10.2) & $51.7(10.0)$ & 0.279 \\
\hline
\end{tabular}


Table 2

Primary and Secondary Outcomes

\begin{tabular}{|c|c|c|c|c|c|c|c|c|c|}
\hline \multirow{2}{*}{$\begin{array}{l}\text { Measure by } \\
\text { Assessment } \\
\text { Mean(SD) }\end{array}$} & \multicolumn{3}{|c|}{ Follow-up time } & \multicolumn{2}{|c|}{$\begin{array}{l}\text { Main effect of } \\
\text { Time }\end{array}$} & \multicolumn{2}{|c|}{$\begin{array}{l}\text { Main effect of } \\
\text { Group }\end{array}$} & \multicolumn{2}{|c|}{$\begin{array}{l}\text { Interaction } \\
\text { effects }\end{array}$} \\
\hline & Baseline & $\begin{array}{l}\text { 6-wk } \\
\text { follow-up }\end{array}$ & $\begin{array}{l}\text { 18-wk } \\
\text { follow-up }\end{array}$ & $F_{\text {time }}$ & $P_{\text {time }}$ & $F_{\text {group }}$ & $P_{\text {group }}$ & $\begin{array}{l}\text { F }_{\text {Groupx }} \\
\text { Time }\end{array}$ & $\begin{array}{l}\mathbf{P}_{\text {Groupx }} \\
\text { Time }\end{array}$ \\
\hline \multicolumn{10}{|l|}{ RMDQ } \\
\hline $\begin{array}{l}\text { Intervention } \\
\text { Group }\end{array}$ & $4.8(2.7)$ & $4.0(3.1)$ & $3.1(2.8)$ & 14.256 & 0.000 & 0.813 & 0.313 & 0.043 & 0.952 \\
\hline Control Group & $4.1(2.5)$ & $3.3(2.1)$ & $2.5(1.7)$ & & & & & & \\
\hline \multicolumn{10}{|l|}{ Average(NRS) } \\
\hline $\begin{array}{l}\text { Intervention } \\
\text { Group }\end{array}$ & $4.7(1.8)$ & $3.4(1.5)$ & $3.4(2.0)$ & 6.394 & 0.004 & 0.515 & 0.478 & 0.477 & 0.624 \\
\hline Control Group & $4.1(1.7)$ & $3.3(1.2)$ & $3.2(1.1)$ & & & & & & \\
\hline \multicolumn{10}{|l|}{ Current(NRS) } \\
\hline $\begin{array}{l}\text { Intervention } \\
\text { Group }\end{array}$ & $3.4(1.8)$ & $2.9(1.5)$ & $2.8(1.8)$ & 3.034 & 0.061 & 0.187 & 0.668 & 0.065 & 0.937 \\
\hline Control Group & $3.3(1.8)$ & $2.6(1.6)$ & $2.5(1.3)$ & & & & & & \\
\hline \multicolumn{10}{|l|}{$\begin{array}{l}\text { Most } \\
\text { severe(NRS) }\end{array}$} \\
\hline $\begin{array}{l}\text { Intervention } \\
\text { Group }\end{array}$ & $6.6(2.0)$ & $5.5(1.8)$ & $4.3(2.0)$ & 27.163 & 0.000 & 0.457 & 0.503 & 0.089 & 0.891 \\
\hline Control Group & $6.2(1.8)$ & $5.2(1.5)$ & 4.1(2.6) & & & & & & \\
\hline \multicolumn{10}{|l|}{ SDS } \\
\hline $\begin{array}{l}\text { Intervention } \\
\text { Group }\end{array}$ & $47.9(11.5)$ & $46.3(11.7)$ & $46.7(9.7)$ & 1.179 & 0.313 & 2.580 & 0.117 & 2.670 & 0.078 \\
\hline Control Group & $41.0(7.3)$ & $45.0(12.4)$ & $40.5(9.9)$ & & & & & & \\
\hline \multicolumn{10}{|l|}{ GAD-7 } \\
\hline $\begin{array}{l}\text { Intervention } \\
\text { Group }\end{array}$ & $4.7(2.8)$ & $4.2(2.7)$ & $4.2(2.9)$ & 1.529 & 0.224 & 0.104 & 0.749 & 3.106 & 0.052 \\
\hline Control Group & $3.3(3.3)$ & $5.2(4.5)$ & $3.7(4.5)$ & & & & & & \\
\hline \multicolumn{10}{|l|}{ PCS(SF-36) } \\
\hline $\begin{array}{l}\text { Intervention } \\
\text { Group }\end{array}$ & $39.5(6.4)$ & $43.6(8.0)$ & $45.8(8.1)$ & 15.459 & 0.000 & 2.456 & 0.126 & 1.283 & 0.282 \\
\hline Control Group & $44.2(7.9)$ & $45.1(6.7)$ & 49.7(8.7) & & & & & & \\
\hline \multicolumn{10}{|l|}{ MCS(SF-36) } \\
\hline $\begin{array}{l}\text { Intervention } \\
\text { Group }\end{array}$ & $48.3(10.2)$ & $47.0(11.4)$ & $48.0(10.6)$ & 0.860 & 0.420 & 0.790 & 0.380 & 0.115 & 0.877 \\
\hline
\end{tabular}




\begin{tabular}{|c|c|c|c|c|c|c|c|c|c|}
\hline \multirow{3}{*}{$\begin{array}{l}\text { Measure by } \\
\text { Assessment } \\
\text { Mean(SD) }\end{array}$} & \multicolumn{3}{|c|}{ Follow-up time } & \multicolumn{2}{|c|}{$\begin{array}{l}\text { Main effect of } \\
\text { Time }\end{array}$} & \multicolumn{2}{|c|}{$\begin{array}{l}\text { Main effect of } \\
\text { Group }\end{array}$} & \multicolumn{2}{|c|}{$\begin{array}{l}\text { Interaction } \\
\text { effects }\end{array}$} \\
\hline & Baseline & 6-wk & 18-wk & $\mathrm{F}_{\text {time }}$ & $P_{\text {time }}$ & $F_{\text {group }}$ & $P_{\text {group }}$ & $F_{\text {Groupx }}$ & $P_{\text {Groupx }}$ \\
\hline & & & & & & & & Time & Time \\
\hline Control Group & $51.4(10.2)$ & $48.7(11.2)$ & $51.2(13.2)$ & & & & & & \\
\hline
\end{tabular}

Table 3

The Treatment Adherence

\begin{tabular}{|c|c|c|c|c|}
\hline Group & $\begin{array}{l}\text { Nonadherence } \\
\mathrm{n}\end{array}$ & $\begin{array}{l}\text { Incomplete adherence } \\
\mathrm{n}\end{array}$ & $\begin{array}{l}\text { complete adherence } \\
\text { n }\end{array}$ & $\begin{array}{l}\text { The adherence rate } \\
\text { n (\%) }\end{array}$ \\
\hline $\begin{array}{l}\text { Intervention Group } \\
(n=20)\end{array}$ & 1 & 9 & 10 & 19(95) \\
\hline Control Group $(n=20)$ & 7 & 7 & 6 & $13(65)$ \\
\hline $\mathrm{P}$ (Fisher) & & & & 0.044 \\
\hline
\end{tabular}

\section{Discussion And Conclusion}

\subsection{Discussion}

We found that both intervention and control groups significantly improved in short-term function at Week 18 , but $\mathrm{m}$ health based exercise (via plus education) did not improve participant outcome. The two groups significantly improved average and most severe pain in the last 2 weeks and the PCS of SF-36 during the course of the 18-week follow-up. As for the secondary outcomes,participants were able to use patient education to treat their anxiety and depression after treatment, but the relief did not last to Week 18. Finally, the intervention group's treatment adherence was significantly higher than that of the control group, and the results were statistically significant $(P=0.044)$.

From the participants' registration information, exercise had proved to be more effective than massage ${ }^{[25] \text {; }}$ unfortunately, only a small percentage of our participants had tried exercise therapy. This outcome was similar to previous study results ${ }^{[26]}$. Patients with low-back pain in under-resourced areas struggled to receive professional guidance, and our m-health based study addressed this problem. In our study, most patients did not receive on-site treatment due to distance and time conflicts, but these inhibitions did not affect treatment progress. Additionally, through detailed participant communication, we found that the participants lacked understanding of low-back pain and maintained negative habits, such as sedentariness, so in the intervention group, we strengthened education and communication, with the aim of teaching the participants positive-intervention habits and self-management ${ }^{[27]}$. Patient education improved treatment adherence in our study, which should be related to strengthening patients' intrinsic motivation ${ }^{[28]}$. However, the intervention group's treatment effect did not show better improvement as compared to the control group, which may be due to the following reasons: this was a pilot study with an insufficient sample size, and the patients' severity and psychological levels in the intervention group were more serious than that of the control group. Therefore, the sample size should be expanded for future study.

The study strengths were that the study was a clinical trials without clinical sites ${ }^{[29]}$, and participants could receive treatments anywhere and anytime ${ }^{[30]}$. Compared to other studies on low-back pain education ${ }^{[31-32]}$, our study was 
more convenient, efficient, and labor-saving effective. In our trial, participants wanted to exercise in their spare time based on the video, and they could ask questions at any time. The online-only recruitment and online-questionnaire collection also simplified the process and saved time, costs, and increased convenience to researchers. The main research site was located in the participants' home, rather than the research center, thus, saving costs. Additionally, the online-treatment therapies prevented COVID-19 exposure due to maintaining social isolation ${ }^{\text {[3] }}$.

However, this study has some limitations. First, the participants were required to complete the exercise program without the supervision of a physical therapist, so we couldn't guarantee if the process completion was at quality standard. Second, the participant number was insufficient, and there was bias between the intervention and control groups on psychological indicator(s); the participants in the intervention group had poorer mental health than the control group.

In future research, we should not only increase the patients' psychological intervention to improve their mental health, but also make full use of advanced information technology to increase the research quality. We should adopt more useful educational measures in future research, such as the Pain Neuroscience Education ${ }^{[34]}$. Combined with psychology methods, such as online cognitive behavioral therapy(CBT $)^{[35]}$ or online mindfulness ${ }^{[35]}$ for treatment, the treatment results may improve.

In conclusion, $\mathrm{m}$-health based exercise guidance is a convenient and effective method to treat CLBP. Additional education is vital for relieving short-term negative emotions and improving treatment adherence. However, at the last follow-up(Week 18), no significant difference was found between the intervention and control groups.

\section{Declarations}

\section{Ethics approval and consent to participate]}

This study was approved by the Institutional Research Ethics Committee of the First Affiliated Hospital, Sun Yat-sen University([2021]078). Electronic informed consent was obtained from all participants included in the study.

\section{Consent for publication $\square$}

Electronic informed consent for publication was obtained from all participants.

\section{Availability of data and materials!}

All data generated or analysed during this study are included in this published article [and its supplementary information files].

\section{Intervention methods [}

All methods were carried out in accordance with relevant guidelines and our clinical experiences.

\section{Competing interests!}

The authors declare no competing financial or non-financial interests.

\section{Funding}


This study was supported by the National Natural Science Foundation of China (81772434) and the Guangdong Basic and Applied Basic Research Foundation (2019A1515110628).

\section{Authors' contributions[}

FMZ and SFL carried out the acquisition and interpretation of data and were the major contributors in drafting the manuscript. SFL carried out the clinical data collection. QHY and TNL carried out the statistical analysis. SSZ,WLAL and $\mathrm{CHW}$ carried out the design of this study, revised the manuscript critically, and all authors gave final approval of the version to be published.

\section{Acknowledgements]}

The authors thank all volunteers who participated in this study. The authors thank AiMi Academic Services (www.aimieditor.com) for English language editing and review services.The authors thank AUK(Exercise training system) for supporting exercise content.

\section{References}

1. Hartvigsen J, Hancock MJ, Kongsted A, Louw Q, Ferreira ML, Genevay S, Hoy D, Karppinen J, Pransky G, Sieper J, Smeets RJ, Underwood M, Buchbinder R, Hartvigsen J, Cherkin D, Foster NE, Maher CG, Underwood M, van Tulder M, Anema JR, Chou R, Cohen SP, Menezes Costa L, Croft P, Ferreira M, Ferreira PH, Fritz JM, Genevay S, Gross DP, Hancock MJ, Hoy D, Karppinen J, Koes BW, Kongsted A, Louw Q, Öberg B, Peul WC, Pransky G, Schoene M, Sieper J, Smeets RJ, Turner JA, Woolf A. What low back pain is and why we need to pay attention. The Lancet 2018, 391(10137): 2356-2367.

2. Collaborators, GBD Diseases And Injuries. Global, regional, and national incidence, prevalence, and years lived with disability for 310 diseases and injuries, 1990-2015: a systematic analysis for the Global Burden of Disease Study 2015. The Lancet 2016, 388(10053): 1545-1602.

3. Collaborators, GBD Diseases And Injuries. Global burden of 369 diseases and injuries in 204 countries and territories, 1990-2019: a systematic analysis for the Global Burden of Disease Study 2019. LANCET 2020, 396(10258): 1204-1222.

4. Finnerup NB. Nonnarcotic Methods of Pain Management. The New England Journal of Medicine 2019, 380(25): 2440-2448.

5. Qaseem A, Wilt TJ, McLean RM, Forciea MA. Noninvasive Treatments for Acute, Subacute, and Chronic Low Back Pain: A Clinical Practice Guideline From the American College of Physicians. ANN INTERN MED 2017, 166(7): 514-530.

6. de Campos TF. Low back pain and sciatica in over 16s: assessment and management NICE Guideline [NG59]. J PHYSIOTHER 2017, 63(2): 120.

7. Stochkendahl MJ, Stochkendahl MJ, Kjaer P, Kjaer P, Hartvigsen J, Hartvigsen J, Kongsted A, Kongsted A, Aaboe $J$, Aaboe J, Andersen M, Andersen M, Andersen M $\varnothing$, Andersen M $\varnothing$, Fournier G, Fournier G, Højgaard B, Højgaard B, Jensen MB, Jensen MB, Jensen LD, Jensen LD, Karbo T, Karbo T, Kirkeskov L, Kirkeskov L, Melbye M, Melbye M, Morsel-Carlsen L, Morsel-Carlsen L, Nordsteen J, Nordsteen J, Palsson TS, Palsson TS, Rasti Z, Rasti Z, Silbye PF, Silbye PF, Steiness MZ, Steiness MZ, Tarp S, Tarp S, Vaagholt M, Vaagholt M. National Clinical Guidelines for non-surgical treatment of patients with recent onset low back pain or lumbar radiculopathy. EUR SPINE J 2018, 27(1): 60-75. 
8. Shamsi M, Mirzaei M, HamediRad M. Comparison of muscle activation imbalance following core stability or general exercises in nonspecific low back pain: a quasi-randomized controlled trial. BMC Sports Sci Med Rehabil 2020, 12: 24.

9. Barbari V, Storari L, Ciuro A, Testa M. Effectiveness of communicative and educative strategies in chronic low back pain patients: A systematic review. PATIENT EDUC COUNS 2020, 103(5): 908-929.

10. Parreira P, Heymans MW, van Tulder MW, Esmail R, Koes BW, Poquet N, Lin CC, Maher CG. Back Schools for chronic non-specific low back pain. COCHRANE DB SYST REV 2017(CD0116748).

11. Meng K, Peters S, Faller H. Effectiveness of a standardized back school program for patients with chronic low back pain after implementation in routine rehabilitation care. PATIENT EDUC COUNS 2017, 100(6): 1161-1168.

12. Li J, Chen X, Han X, Zhang G. Spatiotemporal matching between medical resources and population ageing in China from 2008 to 2017. BMC PUBLIC HEALTH 2020, 20(1): 1-845.

13. Sander LB, Paganini S, Terhorst Y, Schlicker S, Lin J, Spanhel K, Buntrock C, Ebert DD, Baumeister H. Effectiveness of a Guided Web-Based Self-help Intervention to Prevent Depression in Patients With Persistent Back Pain: The PROD-BP Randomized Clinical Trial. JAMA PSYCHIAT 2020.

14. Du S, Liu W, Cai S, Hu Y, Dong J. The efficacy of e-health in the self-management of chronic low back pain: A meta analysis. INT J NURS STUD 2020, 106: 103507.

15. Yang J, Wei Q, Ge Y, Meng L, Zhao M. Smartphone-Based Remote Self-Management of Chronic Low Back Pain: A Preliminary Study. J HEALTHC ENG 2019, 2019: 1-7.

16. Kissler SM, Tedijanto C, Goldstein E, Grad YH, Lipsitch M. Projecting the transmission dynamics of SARS-CoV-2 through the postpandemic period. SCIENCE 2020, 368(6493): 860-868.

17. Wiersinga WJ, Rhodes A, Cheng AC, Peacock SJ, Prescott HC. Pathophysiology, Transmission, Diagnosis, and Treatment of Coronavirus Disease 2019 (COVID-19): A Review. JAMA 2020.

18. Licciardone JC, Pandya V. Feasibility Trial of an eHealth Intervention for Health-Related Quality of Life: Implications for Managing Patients with Chronic Pain during the COVID-19 Pandemic. Healthcare (Basel) 2020, 8(4).

19. Shariat A, Anastasio AT, Soheili S, Rostad M. Home-based fundamental approach to alleviate low back pain using myofascial release, stretching, and spinal musculature strengthening during the COVID-19 pandemic. Work (Reading, Mass.) 2020, 67(1): 11-19.

20. Yi H, Ji X, Wei X, Chen Z, Wang X, Zhu X, Zhang W, Chen J, Zhang D, Li M. Reliability and validity of simplified Chinese version of Roland-Morris questionnaire in evaluating rural and urban patients with low back pain. PLOS ONE 2012, 7(1): e30807.

21. Morone NE, Greco CM, Moore CG, Rollman BL, Lane B, Morrow LA, Glynn NW, Weiner DK, Cramer H. A Mind-Body Program for Older Adults With Chronic Low Back Pain: A Randomized Clinical Trial. Deutsche Zeitschrift für Akupunktur 2017, 60(1): 30-31.

22. Lam CLK, Tse EYY, Gandek B, Fong DYT. The SF-36 summary scales were valid, reliable, and equivalent in a Chinese population. J CLIN EPIDEMIOL 2005, 58(8): 815-822.

23. Toussaint A, Hüsing P, Gumz A, Wingenfeld K, Härter M, Schramm E, Löwe B. Sensitivity to change and minimal clinically important difference of the 7-item Generalized Anxiety Disorder Questionnaire (GAD-7). J AFFECT DISORDERS 2020, 265: 395-401.

24. Jokelainen J, Timonen M, Keinänen-Kiukaanniemi S, Härkönen P, Jurvelin H, Suija K. Validation of the Zung selfrating depression scale (SDS) in older adults. SCAND J PRIM HEALTH 2019, 37(3): 353-357.

Page $11 / 15$ 
25. Saragiotto BT, Maher CG, Yamato TP, Costa LO, Menezes CL, Ostelo RW, Macedo LG. Motor control exercise for chronic non-specific low-back pain. Cochrane Database Syst Rev 2016(1): D12004.

26. Yongjun Z, Tingjie Z, Xiaoqiu Y, Zhiying F, Feng Q, Guangke X, Jinfeng L, Fachuan N, Xiaohong J, Yanqing L. A survey of chronic pain in China. LIBYAN J MED 2020, 15(1): 1730550.

27. Foster NE, Anema JR, Cherkin D, Chou R, Cohen SP, Gross DP, Ferreira PH, Fritz JM, Koes BW, Peul W, Turner JA, Maher CG, Buchbinder R, Hartvigsen J, Cherkin D, Foster NE, Maher CG, Underwood M, van Tulder M, Anema JR, Chou R, Cohen SP, Menezes Costa L, Croft P, Ferreira M, Ferreira PH, Fritz JM, Genevay S, Gross DP, Hancock MJ, Hoy D, Karppinen J, Koes BW, Kongsted A, Louw Q, Öberg B, Peul WC, Pransky G, Schoene M, Sieper J, Smeets RJ, Turner JA, Woolf A. Prevention and treatment of low back pain: evidence, challenges, and promising directions. The Lancet 2018, 391(10137): 2368-2383.

28. Lonsdale CP, Hall AMP, Murray AM, Williams GCP, McDonough SMP, Ntoumanis NP, University C, Owen KH, Schwarzer RP, Parker PP, Kolt GSP, Hurley DAP. Communication Skills Training for Practitioners to Increase Patient Adherence to Home-based Rehabilitation for Chronic Low Back Pain: Results of a Cluster Randomized Controlled Trial. ARCH PHYS MED REHAB 2017, 98(9): 1732-1743.

29. Cummings SR. Clinical Trials Without Clinical Sites. JAMA INTERN MED 2021.

30. Garg S, Garg D, Turin TC, Chowdhury MFU. Web-Based Interventions for Chronic Back Pain: A Systematic Review. J MED INTERNET RES 2016, 18(7): e139.

31. Costantino C, Romiti D. Effectiveness of Back School program versus hydrotherapy in elderly patients with chronic non-specific low back pain: a randomized clinical trial. Acta bio-medica: Atenei Parmensis 2014, 85(3): $52-61$.

32. Minghelli B, Nunes C, Oliveira R. Effectiveness of a Back School and Postural Education Program on the improvement of literacy about postures and low back pain in adolescents: A 1-year follow-up study. J ORTHOP SCI 2020.

33. Hollander JE, Carr BG. Virtually Perfect? Telemedicine for Covid-19. The New England journal of medicine 2020, 382(18): 1679-1681.

34. Malfliet A, Kregel J, Coppieters I, De Pauw R, Meeus M, Roussel N, Cagnie B, Danneels L, Nijs J. Effect of Pain Neuroscience Education Combined With Cognition-Targeted Motor Control Training on Chronic Spinal Pain: A Randomized Clinical Trial. JAMA NEUROL 2018, 75(7): 808-817.

35. Menga G, Ing S, Khan O, Dupre B, Dornelles AC, Alarakhia A, Davis W, Zakem J, Webb-Detiege T, Scopelitis E, Quinet R. Fibromyalgia: can online cognitive behavioral therapy help? The Ochsner journal 2014, 14(3): 343-349.

36. Segal ZV, Dimidjian S, Beck A, Boggs JM, Vanderkruik R, Metcalf CA, Gallop R, Felder JN, Levy J. Outcomes of Online Mindfulness-Based Cognitive Therapy for Patients With Residual Depressive Symptoms: A Randomized Clinical Trial. JAMA PSYCHIAT 2020.

\section{Figures}




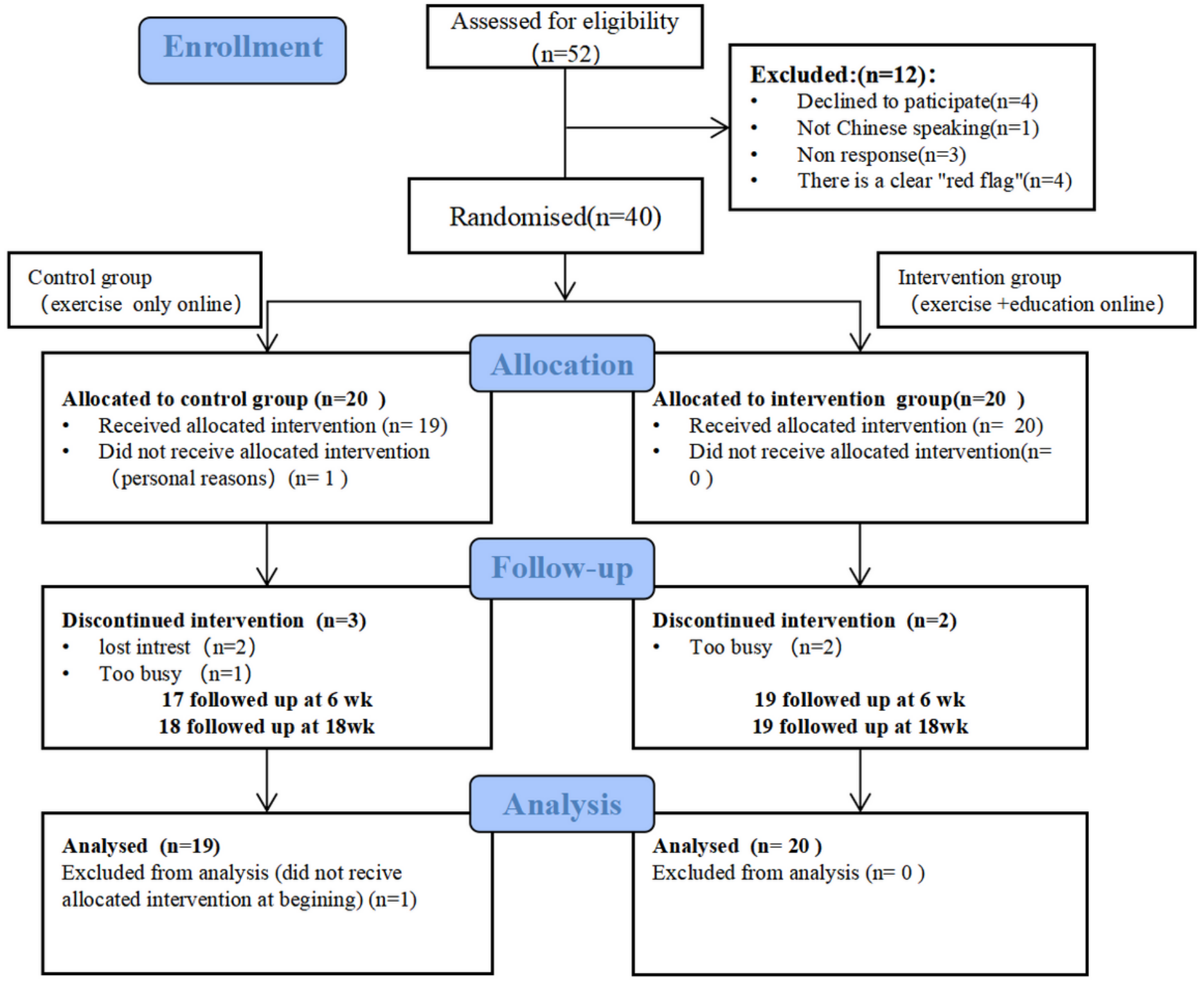

Figure 1

CONSORT Diagram of Study Participation 


\section{Streching (5-10min)}
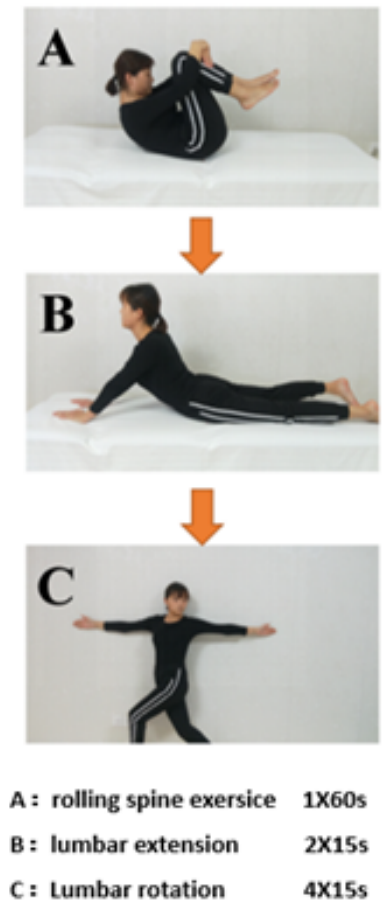

\section{Strenthening (15-25min)}
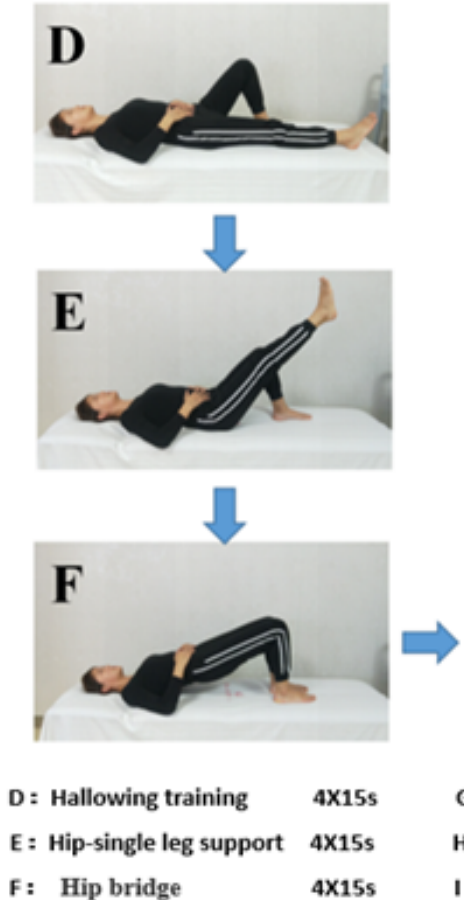
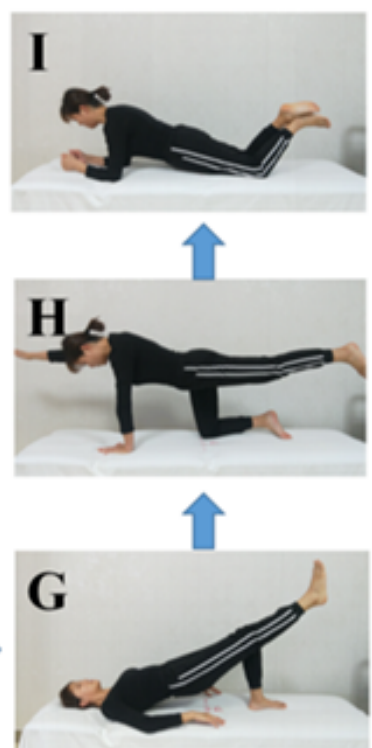

G : Hip-single leg support $4 \times 15$ s $\mathrm{H}$ : Superman action $\quad 4 \times 30$ s I: Half plank $4 \times 30$ s

Figure 2

\section{Exercise Program}

A

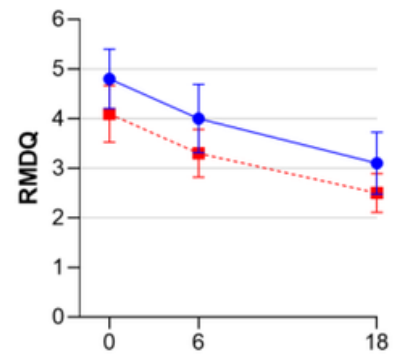

C

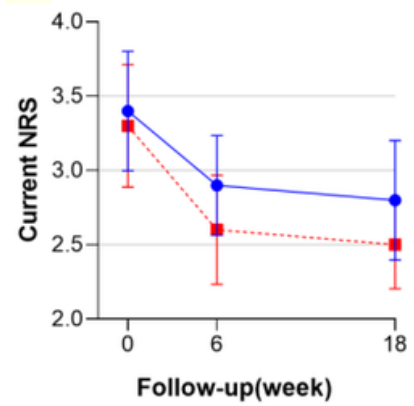

B $\quad$ - Intervention group $E$

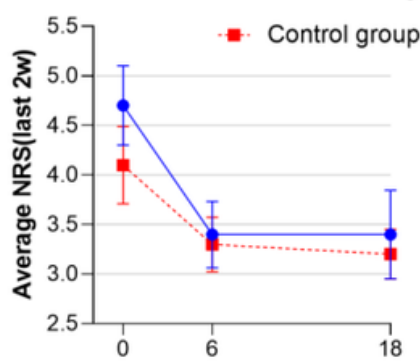

D

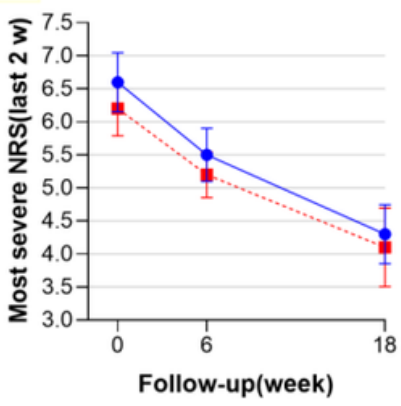

G

Primary outcomes
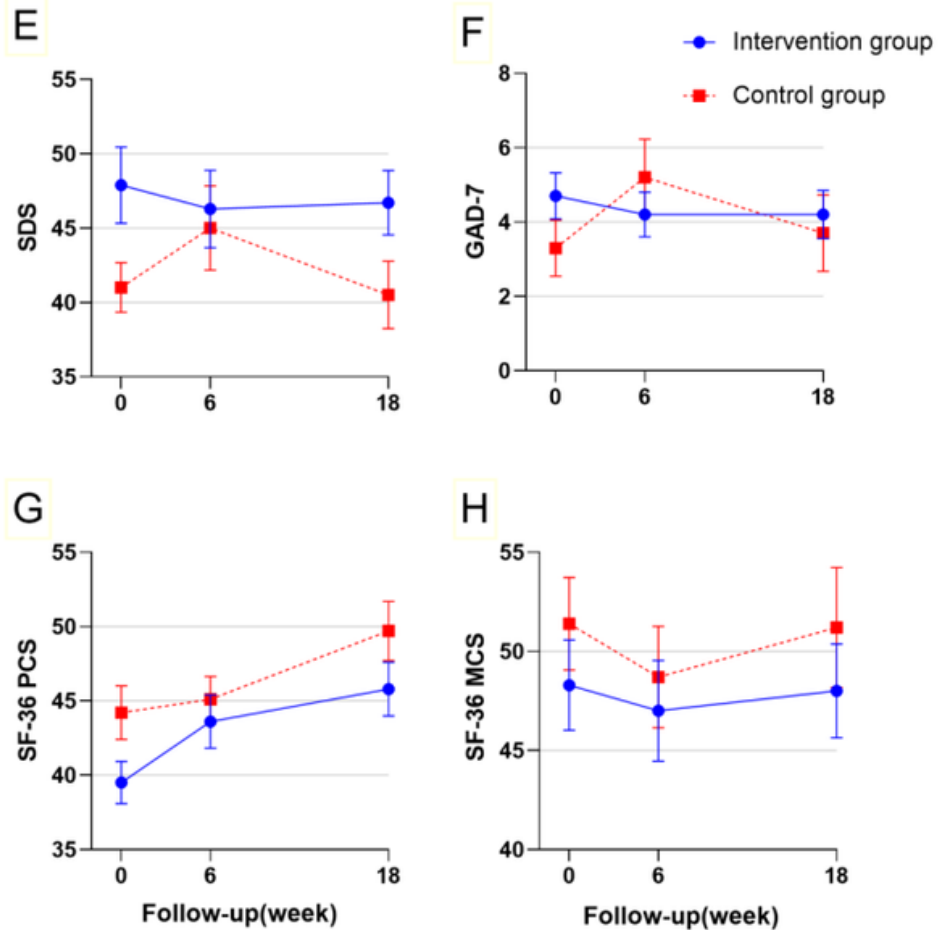

$\mathrm{H}$

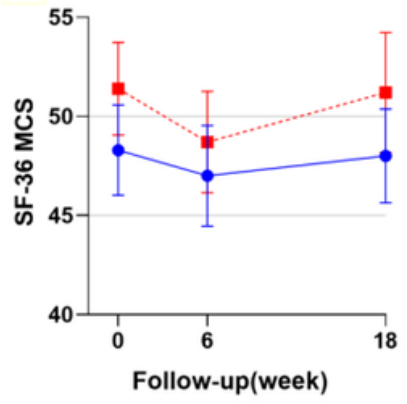

\section{Secondary outcomes}

Figure 3 
Changes in Primary and Secondary Outcomes The within group change (mean, SEM) of primary outcomes are shown

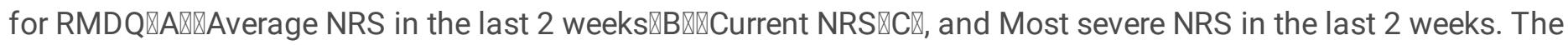

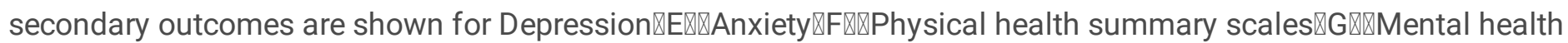
summary scales $₫ \mathrm{H} \rrbracket$.

\section{Supplementary Files}

This is a list of supplementary files associated with this preprint. Click to download.

- rawdata.xls 